\title{
Fracture of aluminium reinforced with densely packed ceramic particles: link between the local and the total work of fracture
}

\author{
A. Miserez, A. Rossoll, A. Mortensen * \\ Laboratory for Mechanical Metallurgy, Institute of Materials, Swiss Federal Institute of Technology in Lausanne (EPFL), \\ MXD, Bâtiment des Matériaux, 1006 Lausanne, Switzerland
}

Received 2 October 2003; received in revised form 17 November 2003; accepted 18 November 2003

\begin{abstract}
Model composites of pure Al reinforced with 50\% ceramic particles are produced by infiltration. The composite fracture energy is measured by $J$-integral testing. Marked $R$-curve behaviour is found. The $J-R$ curves exhibit a break in their slope at a well-defined point. This point is shown to denote the onset of macroscopic crack propagation and is used to assess the composite toughness. Toughness reaches values as high as $40 \mathrm{MPa} \sqrt{\mathrm{m}}$. Quantitative metallography and stereoscopic reconstructions of fracture surfaces are used to estimate the local work of fracture in the process zone. The measured (total) fracture energy is about ten times the estimated local fracture energy, for all composites. The main contribution to their total fracture energy is thus from plastic dissipation around the crack-tip; however, the toughness is still dictated by the local fracture energy. This study hence experimentally substantiates the "valve" concept in fracture mechanics.
\end{abstract}

(C) 2003 Acta Materialia Inc. Published by Elsevier Ltd. All rights reserved.

Keywords: Metal matrix composites; Liquid infiltration; Fracture; Toughness; Valve effect

\section{Introduction}

Particle reinforced metal matrix composites (PRMMCs) are nearly always far less tough than their unreinforced matrix. To understand why, the influence of main microstructural variables such as the type and size of the reinforcement, or the composition and heattreatment of the matrix, have been widely examined; several reviews devoted to the fracture of PRMMCs provide an overview of this large body of information [1-7].

In brief, the ceramic particles cause a strong acceleration of internal damage build-up, and damage is highly localised in front of the crack tip, thus forming a distinct fracture process zone [8-17]. Micromechanisms of fracture operating in this process zone include: (i) particle fracture, (ii) debonding or cracking along the reinforcement/matrix interface, (iii) failure in the matrix by microvoid nucleation, growth and coalescence, and

\footnotetext{
${ }^{*}$ Corresponding author.

E-mail address: andreas.mortensen@epfl.ch (A. Mortensen).
}

(iv) failure in the matrix by shear. While these damage processes may operate simultaneously in a particular composite, one mode is often dominant. Clear tendencies for the effect of microstructural variables on the fracture toughness have however not emerged yet. This is largely because many studies have been conducted on industrially available materials, without the possibility for systematically varying, one by one and independently, main microstructural parameters such as the particle size or the matrix flow stress. As a result, our knowledge of pathways to optimise the fracture toughness of these materials is still incomplete.

One important established point is that well-designed ceramic particle reinforced metals, typically containing up to $30 \mathrm{vol} \%$ ceramic particles, break in a "metallic" fashion: in small-scale yielding (SSY) most of their fracture energy is consumed by plastic deformation around the tip of a moving crack. The fracture process zone is thus surrounded by a much larger plastic deformation zone where most of the fracture energy is consumed, as shown experimentally by different techniques $[7,18,19]$. What links exists between local fracture 
processes that take place directly in the crack tip process zone (i.e., where the composite "cracks") and the total work of fracture of elastic-plastic materials (i.e., the measured fracture toughness) thus takes particular importance for these composites.

Under conditions of SSY, the Orowan-Irwin modification to linear elastic fracture mechanics (LEFM) adds a plastic work term to the Griffith fracture criterion in order to account for the energy consumed by cracktip plasticity [20]. The fracture energy $G_{\mathrm{c}}$ is then given by the well-known equation

$G_{\mathrm{c}}=2 \gamma_{\mathrm{s}}+w_{\mathrm{p}}$,

where $2 \gamma_{\mathrm{s}}$ is the specific surface energy, and $w_{\mathrm{p}}$ is the plastic work of fracture. Because microscopic crack-tip fracture processes in ductile materials are far more complex than the simple creation of two surfaces, a third term that accounts for the energy spent creating the fracture surface profile has been proposed for the ductile fracture of metallic alloys [21-24]. This "local", or "process zone" fracture energy term, $\gamma_{\mathrm{pl}}$, also results from plastic deformation; however, it only accounts for the highly inhomogeneous local microvoiding processes by which ductile materials tear. This term has been linked by Stüwe $[25,26]$ to the flow stress of the microvoiding material and to fractographic parameters, notably the final dimple height, $h$. [18]. The total fracture energy $G_{\mathrm{c}}$ is then written as

$G_{\mathrm{c}}=2 \gamma_{\mathrm{s}}+2 \gamma_{\mathrm{pl}}+w_{\mathrm{p}}$.

It is now recognised that $w_{\mathrm{p}}$ and $2 \gamma_{\mathrm{pz}}=\left(2 \gamma_{\mathrm{s}}+2 \gamma_{\mathrm{pl}}\right) \approx$ $2 \gamma_{\mathrm{pl}}$ (the surface energy term $\gamma_{\mathrm{s}}$ is generally far smaller than $\gamma_{\mathrm{pl}}$ ) are not independent material parameters. Rather, $w_{\mathrm{p}}$ is a direct and increasing function of the local fracture energy, $2 \gamma_{\mathrm{pz}}$, as pointed out in several earlier works [27-29]. Thus, $2 \gamma_{\mathrm{pz}}$ directly governs $G_{\mathrm{c}}$, the term $w_{\mathrm{p}}$ serving only to amplify variations in this local fracture energy. This amplification mechanism has often been referred to as the "valve" effect $[28,30,31]$.

Several analytical approaches have been proposed to describe, for instance, cleavage fracture in the presence of plastic flow, fracture in embrittled materials, in composites, and in other materials to point out in various ways the direct relation that exists between the local term $2 \gamma_{\mathrm{pz}}$ and the total fracture energy $G_{\mathrm{c}}$ [2,30-37]. This link has also been investigated by numerical analysis, in the "local" approach to fracture [38] and using the cohesive zone model (CZM) [39-42]. Using the latter approach for a power-law elastic-plastic material fracturing under SSY conditions and undergoing multiple microvoiding, Tvergaard and Hutchinson [39,40,43-45] together with other authors have shown that in the steady-state fracture regime: (i) the steady-state fracture energy (or toughness) $G_{\mathrm{c}}$ scales proportionally with the "local" cohesive zone fracture energy, and (ii) the constant of proportionality between the two depends mainly on the strain exponent $n$ and the peak stress $\sigma_{\mathrm{p}}$ of the cohesive law.

We present in what follows an experimental study of the fracture toughness of pure aluminium reinforced with densely packed monomodal ceramic particles. Depending on microstructural variables of the composites, namely particle type and size, significant variations are found in the fracture response. To rationalise these variations, the local work of fracture is estimated using quantitative fractography. A comparison can then be drawn between the local and the total fracture energy of these composites: the resulting correlation highlights with clarity both the "valve" effect summarised in what precedes, and the links between the microstructural characteristics of these model composites and their fracture toughness.

\section{Experimental procedures}

\subsection{Materials processing and designation}

The composites were processed by gas-driven pressure infiltration; details can be found in [46-50]. The method allows to process "model" composites that are free of processing defects such as oxide inclusions, uncontrolled interfacial reaction products, or nonuniformly distributed particles ("clustering").

Microstructures were varied by changing the reinforcement chemistry, shape and size. Specifically, three different types of monomodal reinforcement were used: (i) angular-shaped (crushed) $\alpha-\mathrm{Al}_{2} \mathrm{O}_{3}$ powders $(99.5 \%$ purity) with an average reinforcement size ranging from 5 to $35 \mu \mathrm{m}$ (type Alodur ${ }^{\mathrm{TM}}$ WSK, Treibacher Schleifmittel, Laufenburg, Germany); (ii) high purity (99.99\%) polygonal-shaped $\alpha-\mathrm{Al}_{2} \mathrm{O}_{3}$ powders with an average size of 5 to $25 \mu \mathrm{m}$ (Sumitomo Chemicals Co., Ltd., Tokyo, Japan); and (iii) angular $\mathrm{B}_{4} \mathrm{C}$ powders with average sizes ranging from 5 to $60 \mu \mathrm{m}$ (type Tetrabor ${ }^{\mathrm{TM}}$, Elektroschmelzwerk GmbH, Munich, Germany). Significant differences exist between the three powder types regarding the presence of initial defects. In angular $\mathrm{Al}_{2} \mathrm{O}_{3}$ powders cracks are visible under the scanning electron microscope (SEM); $\mathrm{B}_{4} \mathrm{C}$ powders have elliptic pores on their surface, whereas no such flaws are found on the surface of the polygonal $\mathrm{Al}_{2} \mathrm{O}_{3}$ powders [51,52].

High purity (99.99\%) Al (VAW Highpural GmbH, Grevenbroich, Germany) was used for the matrix, thereby preventing the formation of interfacial reaction phases in $\mathrm{Al}_{2} \mathrm{O}_{3}$ reinforced composites. In contrast, some chemical reactivity exists between molten aluminium and $\mathrm{B}_{4} \mathrm{C}$ [53-55]; however, reaction phases can be kept to very small quantities by controlling contact time between molten $\mathrm{Al}$ and the $\mathrm{B}_{4} \mathrm{C}$ particles [56]. Typical microstructures for the three types of composites are given in Fig. 1. Note in particular the homogeneous 


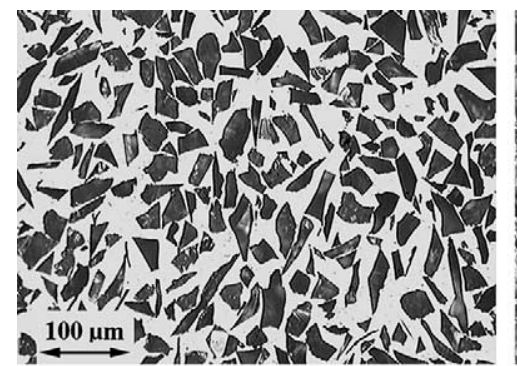

(a)

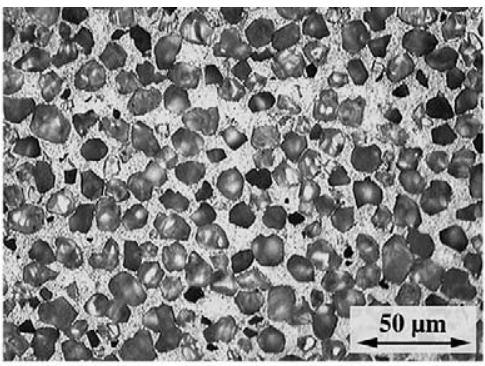

(b)

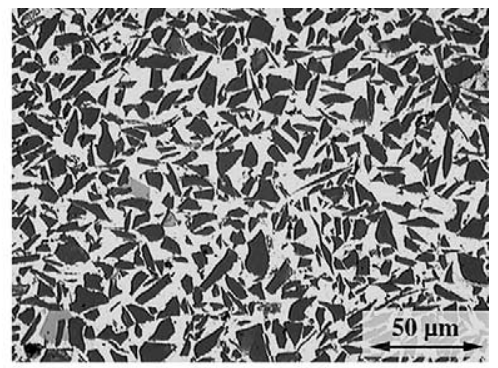

(c)

Fig. 1. Optical micrographs of the composites. (a) $35 \mu \mathrm{m}$ angular $\mathrm{Al}_{2} \mathrm{O}_{3}$ reinforced composite; (b) $15 \mu \mathrm{m}$ polygonal $\mathrm{Al}_{2} \mathrm{O}_{3}$ reinforced composite; (c) $10 \mu \mathrm{m} \mathrm{B} \mathrm{B}_{4} \mathrm{C}$ reinforced composite. The volume fraction of ceramic particles (in dark) ranges between $50 \%$ and $60 \%$.

Table 1

Microstructural characteristics of the composites presented in this study $\left(V_{\mathrm{f}}\right.$ : volume fraction of reinforcement)

\begin{tabular}{cllll}
\hline Matrix & $\begin{array}{l}\text { Reinforcement } \\
\text { type }\end{array}$ & $\begin{array}{l}\text { Average } \\
\text { reinforcement } \\
\text { size }(\mu \mathrm{m})^{\mathrm{a}}\end{array}$ & $\begin{array}{l}V_{\mathrm{f}} \\
\text { (dimension- } \\
\text { less) }\end{array}$ & $\begin{array}{l}\text { Composite } \\
\text { designation }\end{array}$ \\
\hline $\begin{array}{c}\text { Pure } \mathrm{Al} \\
(99.99 \%)\end{array}$ & $\mathrm{Al}_{2} \mathrm{O}_{3}$ & $33 \pm 8$ & 0.45 & $\mathrm{~A} 35 a$ \\
& angular & $9.9 \pm 5$ & 0.54 & $\mathrm{~A} 10 a$ \\
& $3.7 \pm 1.5$ & 0.42 & $\mathrm{~A} 5 a$ \\
& & $25 \pm 7$ & 0.59 & $\mathrm{~A} 25 p$ \\
& $\mathrm{Al}_{2} \mathrm{O}_{3}$ & $15 \pm 4$ & 0.58 & $\mathrm{~A} 15 p$ \\
& polygonal & $5.8 \pm 2$ & 0.56 & $\mathrm{~A} 5 p$ \\
& & $62 \pm 10$ & 0.54 & $\mathrm{~B} 60$ \\
& & $34.5 \pm 9$ & 0.58 & $\mathrm{~B} 35$ \\
& angular & $21.3 \pm 7$ & 0.54 & $\mathrm{~B} 20$ \\
& & $8.0 \pm 2$ & 0.51 & $\mathrm{~B} 10$ \\
& & $5.6 \pm 1.5$ & 0.53 & $\mathrm{~B} 5$ \\
\hline
\end{tabular}

${ }^{\mathrm{a}}$ Medium value of the size distribution, as measured by centrifugal sedimentation.

spatial distribution of the particles within the matrix, and the difference in the microstructural length scales. Some reaction phases for the $\mathrm{Al}-\mathrm{B}_{4} \mathrm{C}$ system are noticed only with the smaller $(5$ and $10 \mu \mathrm{m})$ particles (Fig. 1(c)) for the short processing cycles employed here (see [56] for more details on this system).

The microstructural characteristics of the composites are given in Table 1. In what follows, the composites will be designated as follows: the first letter indicates the chemistry of the particles ( $\mathrm{A}$ for $\mathrm{Al}_{2} \mathrm{O}_{3}$ and $\mathrm{B}$ for $\mathrm{B}_{4} \mathrm{C}$ ), the following number determines the average reinforcement size measured by centrifugal sedimentation. ${ }^{1}$ For $\mathrm{Al}_{2} \mathrm{O}_{3}$ composites a letter is finally added to differentiate between angular $(a)$ or polygonal $(p)$ particles.

\footnotetext{
${ }^{1}$ Some slight differences may appear here with the designation of the same composites in previous papers [63,64]. This is because the nominal size given by the supplier was used previously, whereas we base our denominations on our own more recent and precise measurements, conducted by centrifugal sedimentation.
}

\section{2. $J-R$ curve testing}

These composites are relatively ductile (their strains to failure exceed one percent) and they exhibit a rather low yield strength, of a few hundred MPa [51,57]. $J$ integral method was hence employed to obtain valid toughness data, using the single specimen technique according to ASTM E-1737 [58]. Compact tension (CT) specimens with a thickness of $B$ of $13 \mathrm{~mm}$ and a specimen width $W$ of $20 \mathrm{~mm}$ were cut by electro-discharge machining (EDM), and pre-cracked by fatigue loading on a $25 \mathrm{kN}$ servohydraulic testing machine (Instron model 8872, Canton, MA, USA). A specific procedure was developed to control crack-advance, as described in $[19,52]$.

$J$-integral fracture tests were conducted on a $100 \mathrm{kN}$ screw-driven universal testing machine (Zwick, Ulm, Germany). The crack mouth opening displacement (CMOD) was monitored on the load line, and the tests were conducted under crosshead control at a velocity of $50 \mu \mathrm{m} / \mathrm{nm}$. Crack advance was computed by performing unloading/reloading cycles at regular load increments.

Since the composite samples exhibit a macroscopically ductile fracture behaviour, their response is strongly affected by three-dimensional effects, as shown in [19]. Because this may induce a dependence of specimen geometry on $J-R$ curves [59-61], side-grooves were machined along the side of some specimens to ensure dominance of plane-strain conditions along the crack front. The net section of the side-grooved specimens was $80 \%$ of the gross thickness, with a V-shape groove angle of $45^{\circ}$.

\subsection{Identification and quantification of fracture micro- mechanisms}

Crack tip fracture micromechanisms were investigated by arresting fracture tests on chevron-notched specimens prior to catastrophic fracture. Rapid adhesive bond was subsequently introduced within the open crack, and the specimens were sectioned and observed in profile by optical light microscopy. The method allows 
observation of both sides of the crack, such that there is no ambiguity distinguishing particle fracture and interfacial debonding.

Dominant modes of fracture within each composite were quantified by acquiring a high number of digital pictures along the crack path and by counting the total number of broken particles along segments of the crack path. The fraction of the crack path $f_{\mathrm{b}}$ occupied by broken particles was estimated as

$f_{\mathrm{b}}=\frac{D \cdot N}{L_{X} \cdot L}$,

where $D$ is the average particle size in $\mu \mathrm{m}, N$ is the total number of counted broken particles, $L_{X}$ is the pixel size in $\mu \mathrm{m} / \mathrm{pixel}$, and $L$ is the total crack length analysed, in pixels.

\subsection{SEM fractography and determination of dimple size by stereophotogrammetry}

Uncoated fracture surfaces were examined by SEM, using a Philips XL-30 electron microscope. Additional fractography was performed under an "Olympus SZX12" stereomicroscope (Olympus Optical Co., Tokyo, Japan), as this provides a clear contrast between the fatigue crack propagation mode and the ductile fracture mode.

In order to obtain quantitative information of the fractured surface profiles, the "MEX" stereophotogrammetry software (Alicona Imaging $\mathrm{GmbH}$, Grambach, Austria) allowing three-dimensional reconstruction of fracture surfaces from SEM pictures, was employed; see $[62,63]$ for more details on the software.

Quantitative features of the fracture surface profiles were thus determined, including surface roughness and accurate measurements of local height differences. At least three DEMs were generated at various magnifications, from which individual dimple heights were measured. A minimum of twenty dimples were measured for each sample, from which the average dimple size of the fractured composites was calculated.

\section{Results}

\section{1. $J-R$ curves}

\subsubsection{General characteristics and definition of a critical fracture parameter}

The composites exhibit significant $R$-curve behaviour that depends strongly on the particle type and size. Generally speaking, the $J-R$ curves can be divided into three distinct domains, schematically depicted in Fig. 2.

(i) A steep initial part, attributed in unreinforced metallic alloys to crack-tip blunting [64]. In the present

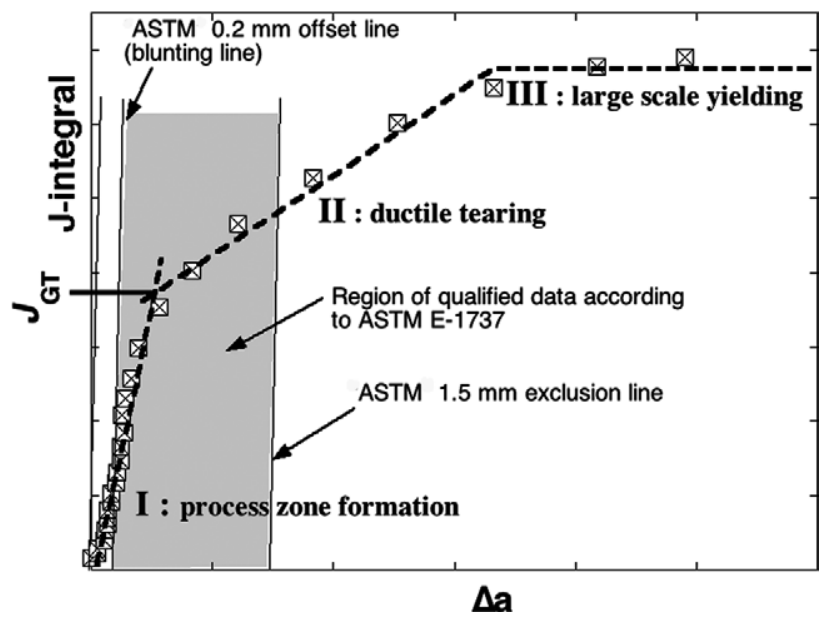

Fig. 2. Typical $J-R$ curves of the composites, illustrating the three different regimes of crack propagation. The initiation of macroscopic crack propagation corresponds to the transition from I to II. Unstable fracture generally occurred for small particle size composites after the onset of Regime II.

composites, some apparent crack extension occurs in this domain due to internal damage build-up near the crack tip.

(ii) A second region of lower slope then starts close to, or at, maximum load. As will be shown below, this region corresponds to macroscopic crack propagation. For the finer particle sizes $(10$ or $5 \mu \mathrm{m})$, the crack often propagates in an unstable manner in this second portion of the $J-R$ curve, slightly after the peak load.

(iii) When fully stable crack propagation occurs, a plateau value is finally attained in a region well beyond the validity domain of $J$-controlled fracture.

These characteristics of the $J-R$ curves raise the question of how crack initiation can be defined in these composites ( $J_{\text {Ic }}$ in unreinforced alloys). The intercept of the resistance curve with the $0.2 \mathrm{~mm}$ offset blunting line as defined in ASTM E-1737 has no fundamental meaning and is even more questionable with the present composites, since crack blunting is altogether different compared to unreinforced alloys. To obtain a critical value of $J$ that has a physical meaning and that can be used to compare the different composites, we use the physical definition of initiation toughness, which corresponds to the onset of stable crack growth [64]. This corresponds to the transition from Region I to Region II on the $J-R$ curves, since this is accompanied by a rapid rate of increase in specimen compliance, denoting a sudden increase in the crack propagation rate. We thus define the initiation of macroscopic crack propagation at the transition between the first and the second regions of the curves. To compute this parameter two regression lines were drawn for each part (I and II) of the curves and the critical value of $J$ was defined at the intersection point of the regression curves, and denominated " $J_{\mathrm{GT}}$ " 
as illustrated in Fig. 2. This choice is further justified in Appendix A.

$J$-validity was assessed according to the analysis of Hutchinson and Paris [65,66], by verifying the condition

$\omega \equiv \frac{b}{J_{\mathrm{R}}} \frac{\mathrm{d} J_{\mathrm{R}}}{\mathrm{d} \Delta a}>10$,

where $\omega$ is an adimensional parameter that equals about 10 for the CT geometry. This verification is plotted in Fig. 3 for polygonal $\mathrm{Al}_{2} \mathrm{O}_{3}$ reinforced composites. $J_{\mathrm{GT}}$ values are also indicated on the plots. For all composites, $J_{\mathrm{GT}}$ value at the onset of ductile tearing falls in the validity domain and can therefore be used as a single fracture toughness parameter of the materials. As soon as extensive crack propagation occurs, $J$ is no longer a valid crack-growth parameter. The loss of $J$-validity is hence induced by rapid crack extension, namely by the relatively large region of elastic unloading behind the crack tip [66].

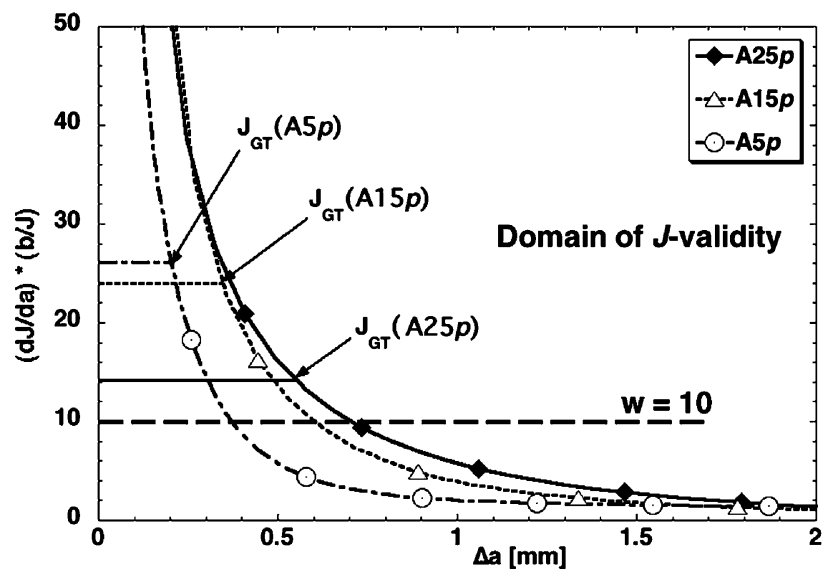

Fig. 3. Verification of $J$-validity for polygonal particle reinforced composites. The critical fracture parameter $J_{\mathrm{GT}}$ always falls within the domain of $J$-controlled crack growth.
From this verification of $J$-dominance and crack arrest experiments (Appendix A), it is concluded that (i) $J_{\mathrm{GT}}$ is a critical value corresponding to the initiation of macroscopic crack propagation, and (ii) that $J_{\mathrm{GT}}$ is a material parameter that is, according to theory, independent of specimen geometry. We use this parameter to compare the different composites.

\subsubsection{Influence of the particle characteristics}

The fracture resistance is clearly influenced by the particle size no matter what the reinforcement type: in each class of composites, $R$-curve behaviour is more pronounced as the particle size increases, Fig. 4. As the particle size decreases, $J_{\mathrm{GT}}$ clearly diminishes and unstable fracture tends to occur earlier. In particular, none of the $5 \mu \mathrm{m}$ particle size composites exhibited stable macroscopic crack propagation after the slope transition in $J-R$ curve.

A comparison of $J-R$ curves for different composites with roughly equivalent reinforcement size is given in Fig. 5. These curves show unambiguously that, for large (Fig. 5(a)) and medium (Fig. 5(b)) reinforcement diameters, composite with polygonal $\mathrm{Al}_{2} \mathrm{O}_{3}$ reinforcement yield the highest toughness, followed by $\mathrm{B}_{4} \mathrm{C}$ reinforced composites, while angular $\mathrm{Al}_{2} \mathrm{O}_{3}$ composites lead to the lowest toughness. As the average reinforcement size decreases, these differences become less obvious, Fig. 5(c). These differences point out in a clear manner the importance of the intrinsic characteristics of the ceramic particles.

\subsubsection{Influence of specimen geometry}

A comparison of $J-R$ curves measured on sidegrooved and flat faced specimens is plotted in Fig. 6 . The fracture energy at the initiation of ductile tearing, $J_{\mathrm{GT}}$, remains almost unaffected by the presence of sidegrooves, further justifying use of the critical toughness $J_{\mathrm{GT}}$ defined earlier.
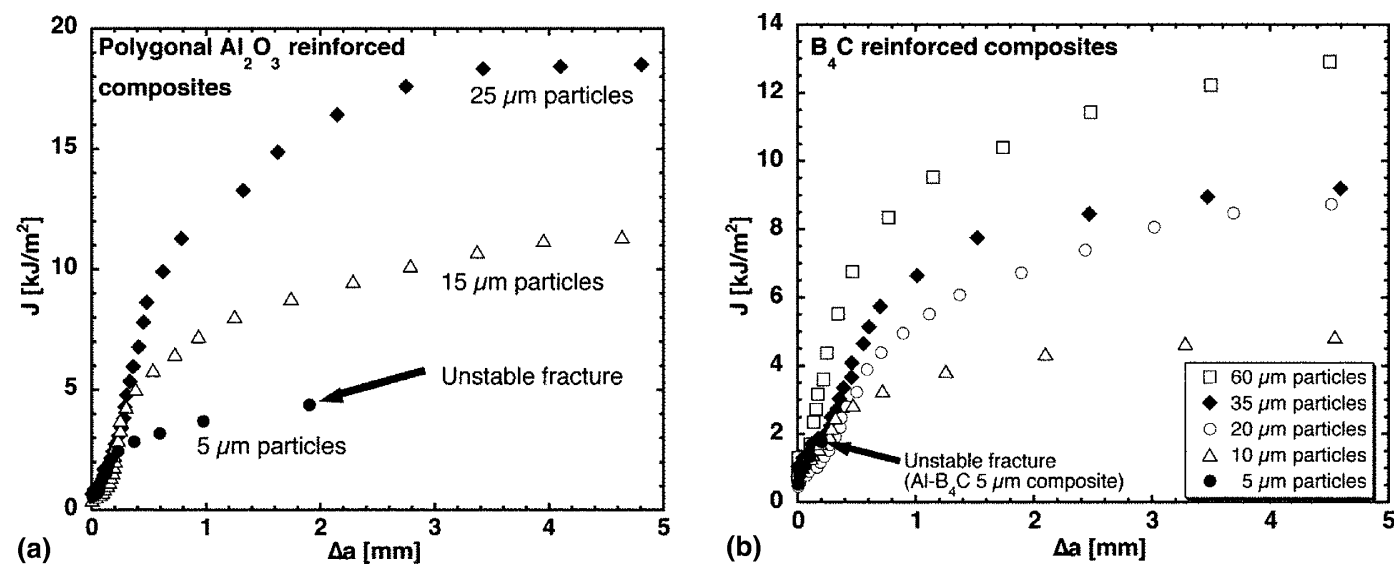

Fig. 4. Influence of particle size on the $J-R$ curves. (a) Polygonal $\mathrm{Al}_{2} \mathrm{O}_{3}$ reinforced composites; (b) $\mathrm{B}_{4} \mathrm{C}$ reinforced composites. 

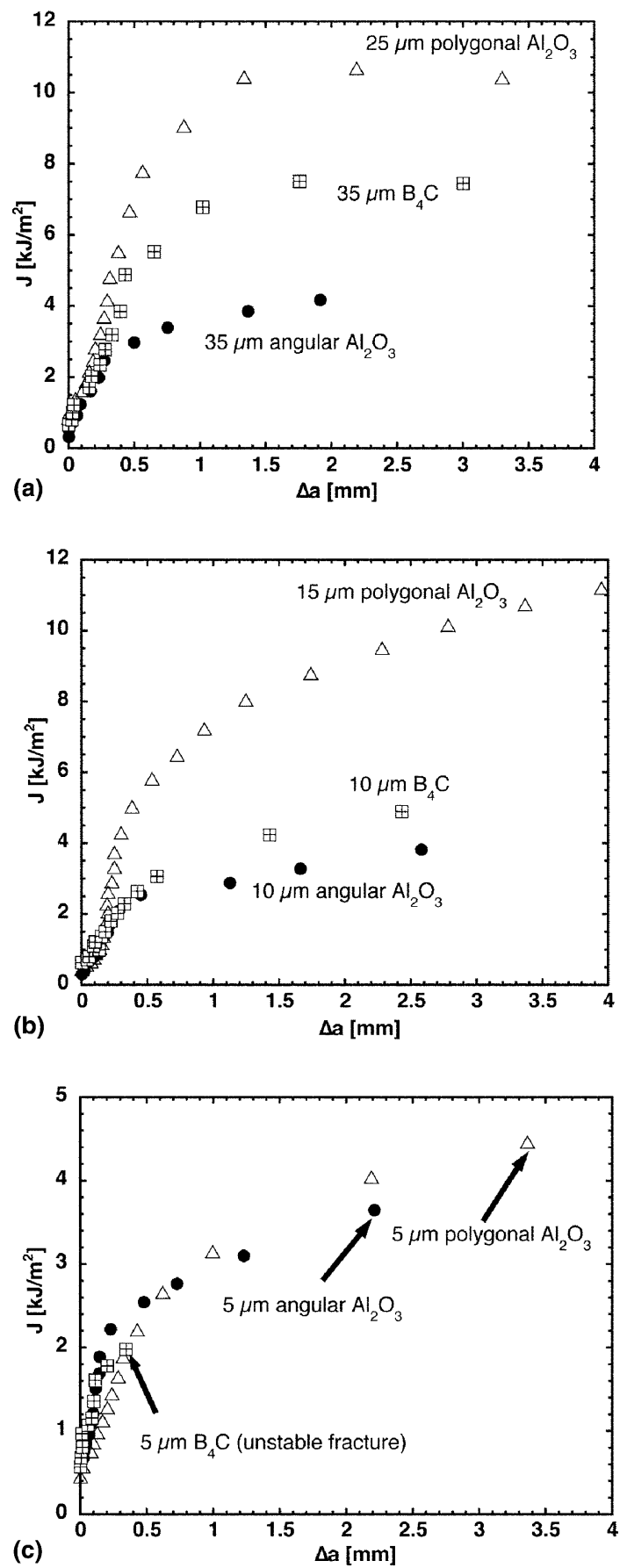

Fig. 5. Influence of the particle type on the $J-R$ curves. (a) Large (25$35 \mu \mathrm{m}$ ) particle size composites; (b) medium $(10-15 \mu \mathrm{m})$ particle size composites, (c) small $(5 \mu \mathrm{m})$ particle size composites.

Once the ductile tearing regime sets in, the effect constraint increases and becomes more visible with materials exhibiting extensive $R$-curve behaviour, Fig. 6(a). In smaller particle size composites, sidegrooves led to systematically unstable fracture slightly after the peak-stress. The occurrence of unstable fracture in side-grooved specimens corresponds to the onset of ductile tearing for the non side-grooved specimens. This is illustrated in Fig. 6(b) for the A5p composite.

\subsubsection{Data summary}

The critical fracture values are summarised in Table 2 for all composites. Tensile characteristics from $[51,57]$ are also included. The minimum specimen size, $B_{\mathrm{c}}$, according to ASTM E-1737 is indicated: since the specimen thickness is $13 \mathrm{~mm}$, all data satisfy ASTM requirements. Critical fracture parameters versus the average particle size are plotted in Fig. 7. The polygonal $\mathrm{Al}_{2} \mathrm{O}_{3}$ composites exhibit the largest toughness for a given particle size, while angular $\mathrm{Al}_{2} \mathrm{O}_{3}$ composites show the lowest toughness. Toughness increases as the average particle size increases for all three particle types, except that A5a composite exhibits a slightly larger fracture energy than the A10a composite (but this difference almost vanishes when toughness is expressed in terms of $K$ because it is compensated by the higher Young's modulus of the A10 $a$ composite). There exists one strong exception to the particle size effect: the A20a composite (shown in brackets in Fig. 7) clearly exhibits the lowest fracture energy of all composites. This is a special case that will be clarified later.

\subsection{Fracture micromechanisms}

\subsubsection{Crack arrest profiles}

Optical micrographs along the crack path of the various composites are shown in Fig. 8. In angular $\mathrm{Al}_{2} \mathrm{O}_{3}$ composites, the dominant fracture mode is particle fracture for 35 and $10 \mu \mathrm{m}$ particle sizes. Failure is hence governed by particle fracture in the process zone, which subsequently nucleates voids in the matrix. For smaller $(5 \mu \mathrm{m})$ particles, little particle fracture is observed. In the $20 \mu \mathrm{m}$ particle composite (the "special case" mentioned above), the crack propagates by decohesion at the particle/matrix interface, Fig. 8(c). Only this composite displayed this type of fracture.

Crack profiles of polygonal $\mathrm{Al}_{2} \mathrm{O}_{3}$ composites are shown in Fig. 8(d) and (e). Here the cracks propagate predominantly through the matrix, by a ductile mechanism of matrix voiding. There are only a few broken particles along the crack path for the larger 25 $\mu \mathrm{m}$ particle size composite, Fig. 8(d). A higher magnification SEM micrograph of the same composite that was electropolished prior to observation is displayed in Fig. 8(e): it illustrates how the crack passes through the matrix, bypassing the particles and leaving them intact.

Arrested crack profiles of $\mathrm{B}_{4} \mathrm{C}$ composites are presented in Fig. 8(f) and (g). For the largest particles (B60), there is approximately an equivalent number of cavities nucleated in the matrix and by particle cracking. For all other, smaller, particle composites, less particle 

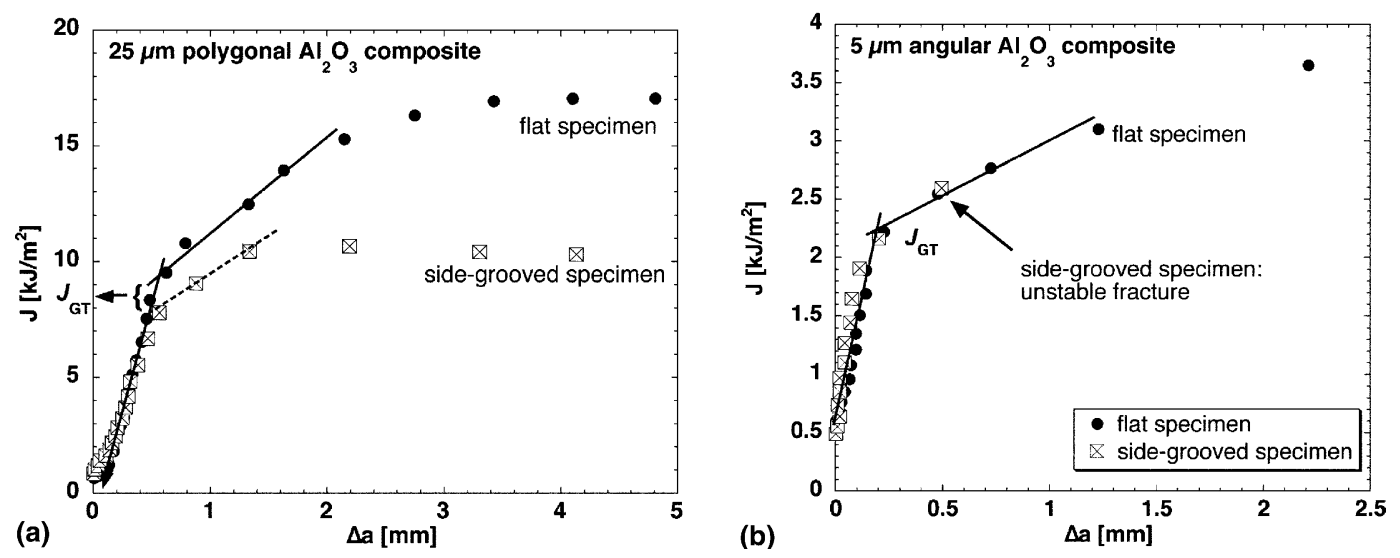

Fig. 6. Influence of the specimen geometry on the $J-R$ curves. (a) Large particle size composites (A25p); (b) small particle size composites (A5a). Until initiation of ductile tearing, $J$ is independent of the specimen geometry. For composites with important $R$-curve behaviour, once macroscopic crack propagation has set in, the $J-R$ curves depend on the specimen geometry.

Table 2

Fracture toughness (defined at the onset of ductile tearing or at unstable fracture in the absence of ductile tearing), and tensile characteristics of the composites

\begin{tabular}{|c|c|c|c|c|c|c|c|}
\hline Composite & $\begin{array}{l}J_{\mathrm{GT}} \\
\left(\mathrm{kJ} / \mathrm{m}^{2}\right)\end{array}$ & $\begin{array}{l}K_{\text {eq-GT }} \\
(\mathrm{MPa} \sqrt{\mathrm{m}})\end{array}$ & $\begin{array}{l}E \\
(\mathrm{GPa})\end{array}$ & $\begin{array}{l}0.2 \% \text { yield strength, } \\
\sigma_{0.2}(\mathrm{MPa})\end{array}$ & $\begin{array}{l}\text { Ult. tensile strength, } \\
\sigma_{\text {UTS }}(\mathrm{MPa})\end{array}$ & $\begin{array}{l}\text { Strain to failure, } \\
\varepsilon_{\mathrm{f}}(\%)\end{array}$ & $\begin{array}{l}B_{\mathrm{c}} \\
(\mathrm{mm})\end{array}$ \\
\hline $\mathrm{A} 35 a$ & 3.1 & 21.6 & 141 & 80 & 125 & 3.2 & 0.8 \\
\hline $\mathrm{A} 20 a$ & 1.2 & 13.9 & 148 & 91 & 114 & 0.6 & 0.3 \\
\hline $\mathrm{A} 10 a$ & 1.8 & 17.0 & 164 & 134 & 194 & 1.8 & 0.25 \\
\hline $\mathrm{A} 5 a$ & 2.2 & 17.6 & 133 & 154 & 245 & 2.6 & 0.3 \\
\hline $\mathrm{A} 25 p$ & 8.5 & 40.4 & 175 & 117 & 189 & 4.1 & 1.4 \\
\hline $\mathrm{A} 15 p$ & 5.4 & 32.5 & 175 & 120 & 230 & 4.5 & 0.8 \\
\hline $\mathrm{A} 5 p$ & 2.6 & 22.2 & 176 & 158 & 190 & 0.6 & 0.4 \\
\hline B 60 & 7.1 & 35.9 & 169 & 91 & 132 & 2.6 & 1.6 \\
\hline B35 & 5.4 & 32.6 & 185 & 133 & 204 & 2.6 & 0.8 \\
\hline $\mathrm{B} 20$ & 4.0 & 27.3 & 170 & 119 & 194 & 2.6 & 0.6 \\
\hline B10 & 3.2 & 23.5 & 161 & 173 & 273 & 2.4 & 0.4 \\
\hline B5 & 2.1 & 19.1 & 167 & 167 & 273 & 2.9 & 0.2 \\
\hline
\end{tabular}

The minimum specimen size requirement according to ASTM E-1737, $B_{\mathrm{c}}$, is also included in the table. The specimen thickness being $13 \mathrm{~mm}$, all data satisfy the standard.
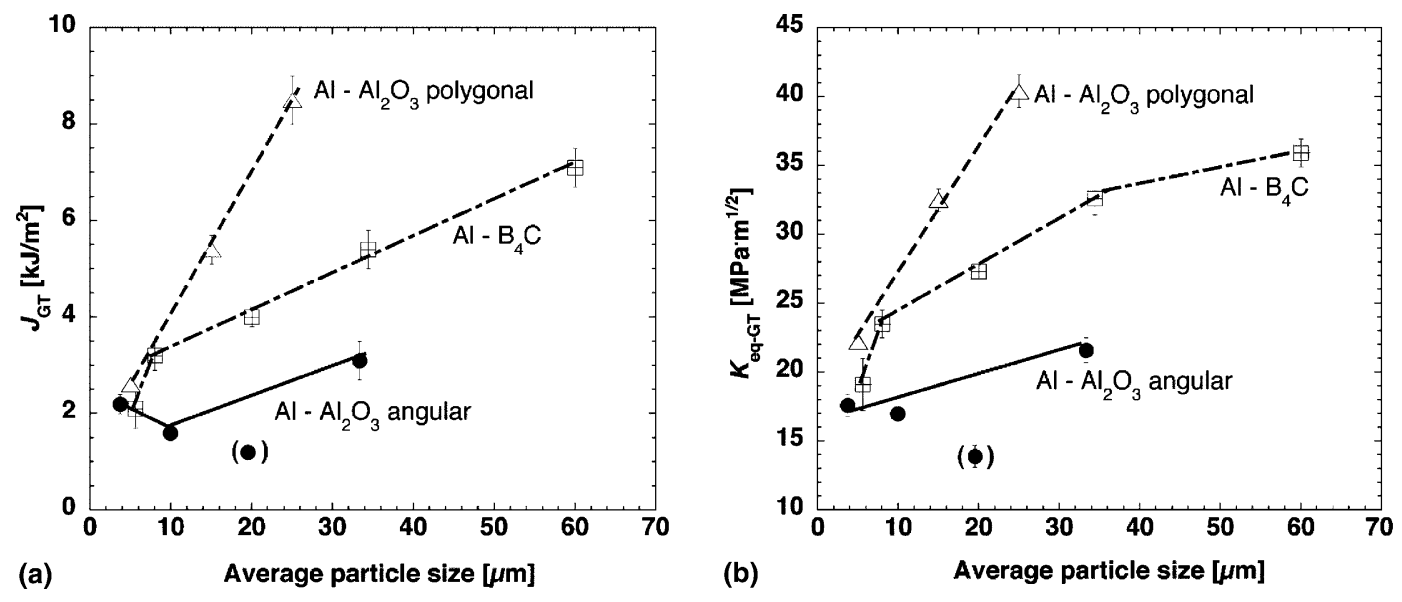

Fig. 7. Composite fracture toughness vs. average reinforcement size, expressed in terms of (a) $J$-fracture energy, $J_{\mathrm{GT}}$, and (b) the corresponding equivalent stress intensity factor, $K_{\text {eq-GT }}$. 


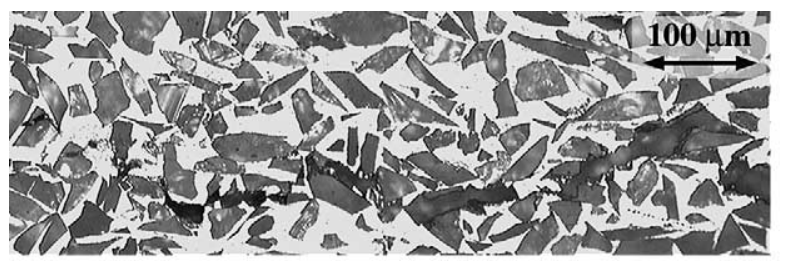

(a)

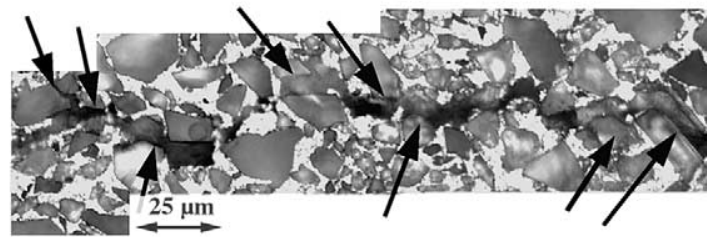

(b)
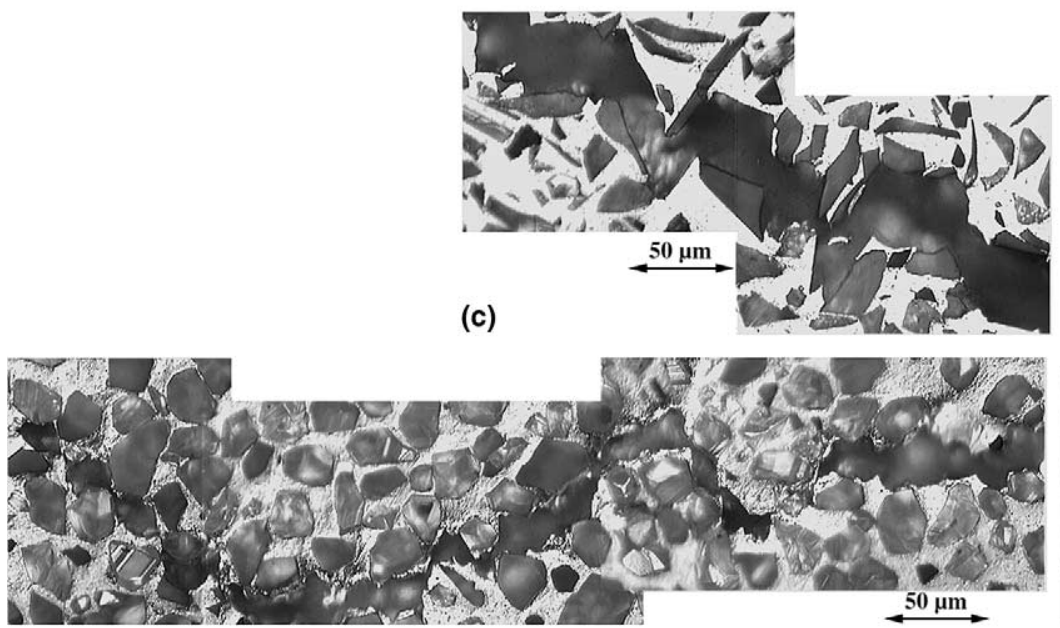

(d)

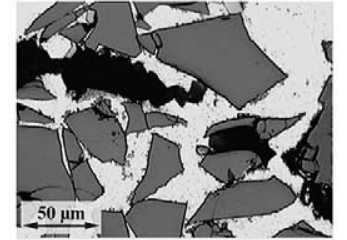

(f)

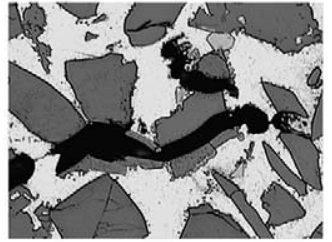

(g)

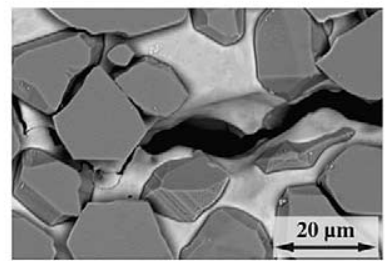

(e)

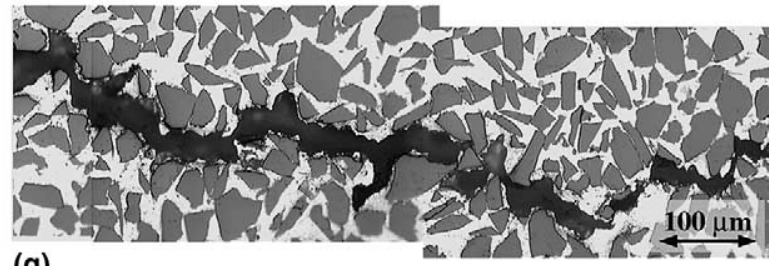

Fig. 8. Micromechanisms of crack propagation in the composites. Tests on chevron-notched specimens were arrested prior to failure, and glue was inserted to preserve the crack opening. The abbreviations of the dominant mechanisms are: "PF" for particle fracture, "MV" for matrix voiding, and "ID" for interfacial decohesion. (a) Angular $35 \mu \mathrm{m}$ composite (PF); (b) angular $10 \mu \mathrm{m}$ composite (PF), arrows indicate fractured particles; (c) angular $20 \mu \mathrm{m}$ composite (ID); (d) polygonal $25 \mu \mathrm{m}$ composite (MV); (e) same composite, SEM micrograph after electropolishing; (f) $60 \mu \mathrm{m}$ B ${ }_{4} \mathrm{C}$ composite (PF and MV); (g) $35 \mu \mathrm{m}$ composite (MV).

cracking occurs and voids are mainly nucleated inside the matrix, (Fig. 8(g) for the B35 composite). For the B5 composite matrix voiding is also the dominant failure mode; however, some cracking of reaction phases was detected as well.

\subsubsection{SEM fractography}

SEM fractographs of angular $\mathrm{Al}_{2} \mathrm{O}_{3}$ composites (Fig. 9(a)-(c)) complement the crack path profiles. In the A35a (Fig. 9(a)) and the A10a composites broken particles are found at the bottom of relatively large dimples, confirming that the large voids are nucleated by broken particles. For the A20a composite, the interfacial failure mode is confirmed by the presence of a secondary crack on the image, where interfacial debonding can unambiguously be detected. In the A $5 a$ composite (Fig. 9(c)), the fracture surface is made of fine dimples with very few broken particles.
SEM fractographs of polygonal $\mathrm{Al}_{2} \mathrm{O}_{3}$ composites (Fig. 9(d)-(f)) confirm clearly ductile failure mode by matrix micro-cavitation. These images also illustrate that the size of the ductile dimples scales with the microstructural length scale of the composites: the size of microcavities is proportional to the particle size (and hence to the interparticle distance). This is consistent with nucleation of the voids at the narrowest regions of matrix between two closely spaced particles.

Fractographic observations by SEM of $\mathrm{B}_{4} \mathrm{C}$ composites are presented in Fig. 9(g)-(i). While fracture occurs mainly by matrix voiding in the large particle size composites (B60), a significant degree of particle fracture can be detected. However, this is clearly less as compared to the angular $\mathrm{Al}_{2} \mathrm{O}_{3}$ composites. As in the polygonal $\mathrm{Al}_{2} \mathrm{O}_{3}$ composites, the dimple size scales with the average particle size and with the interparticle distance. Broken particles are no longer observed in 


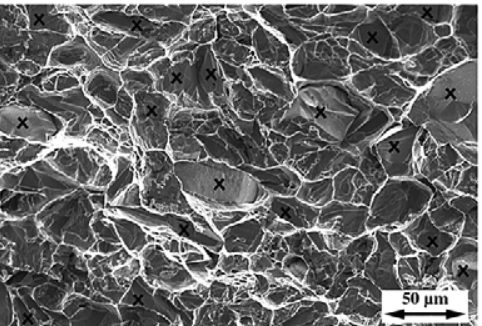

(a)

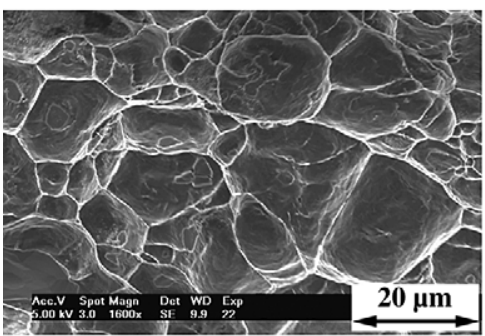

(d)

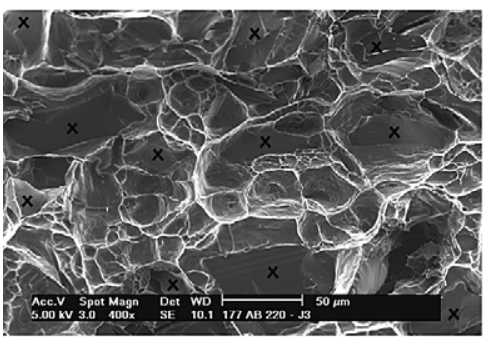

(g) secondary crack (interfacial decohesion)

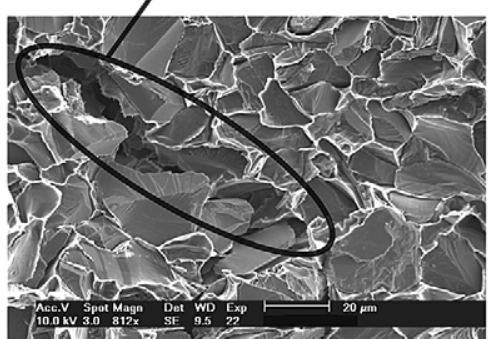

(b)

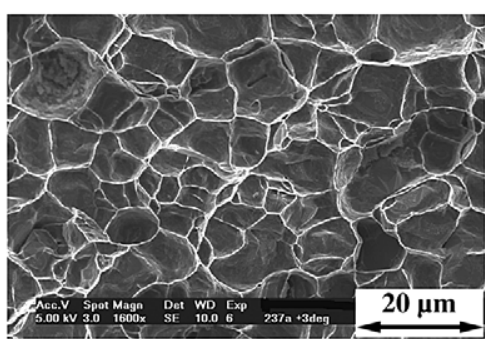

(e)

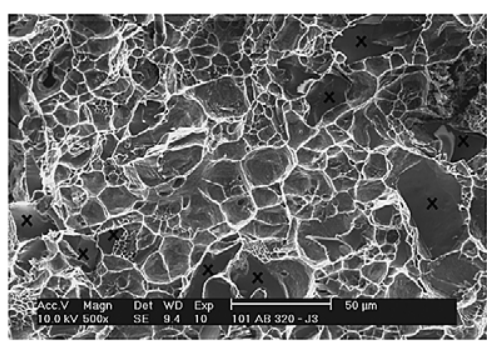

(h)

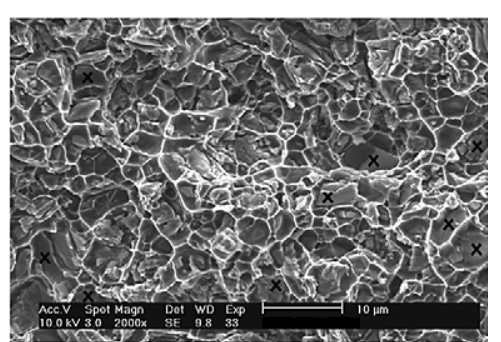

(c)

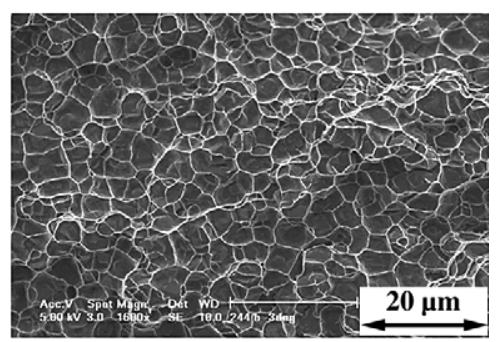

(f)

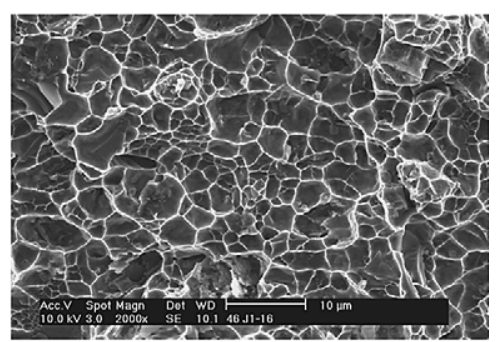

(i)

Fig. 9. SEM fractographs of the composites. (a) A35a composite (broken particles indicated by crosses $\times$ ); (b) A20a composite; (c) A5a composite; (d) A25p composite; (e) A15p composite; (f) A5p composite; (g) B60 composite; (h) B35 composite, (i) B5 composite.

the fine $5 \mu \mathrm{m}$ particle size reinforced composites (Fig. 9(i)).

\subsubsection{Stereophotogrammetry}

Comparison of typical individual dimple profiles in the different composites is presented in Fig. 10. In all composite systems, the cavity depth (which is related to the extent of local plastic deformation during voiding) scales with the average interparticle distance. In a given composite with a given size of reinforce- ment, the depth of dimples nucleated by broken particles (A35a composite, Fig. 10(a)) is larger than when the dimples are nucleated inside the matrix (B35 composite, Fig. 10(c)).

Observations relating to the micromechanisms of fracture are summarised in Table 3: (i) in composites failing by fully ductile matrix voiding, the dimple size scales with the average particle size (Fig. 10(b)); (ii) when particle cracking occurs, the dimple matrix scales with the particles responsible for dimple nucleation;
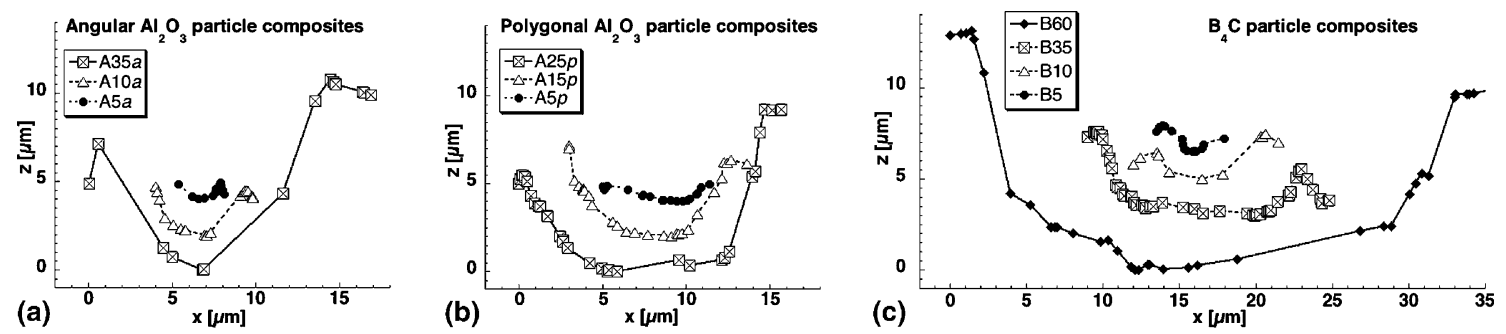

Fig. 10. Typical individual dimple profiles obtained from the digitally reconstructed fracture surfaces. (a) angular $\mathrm{Al}_{2} \mathrm{O}_{3}$ composites; (b) polygonal $\mathrm{Al}_{2} \mathrm{O}_{3}$ composites; (c) $\mathrm{B}_{4} \mathrm{C}$ composites. 
Table 3

Summary of micomechanisms of fracture in the composites

\begin{tabular}{|c|c|c|c|c|}
\hline $\begin{array}{l}\text { Composite } \\
\text { system }\end{array}$ & $\begin{array}{l}\text { Composite } \\
\text { designation }\end{array}$ & Dominant micromechanism of fracture & $\begin{array}{l}\text { Fraction of the crack path } \\
\text { occupied by broken particles, } \\
f_{\mathrm{b}} \text { (dimensionless) }\end{array}$ & $\begin{array}{l}\text { Average ductile } \\
\text { dimple height }(\mu \mathrm{m})\end{array}$ \\
\hline $\begin{array}{l}\mathrm{Al}-\mathrm{Al}_{2} \mathrm{O}_{3} \\
\text { Angular }\end{array}$ & $\begin{array}{l}\mathrm{A} 35 a \\
\mathrm{~A} 20 a \\
\mathrm{~A} 10 a \\
\mathrm{~A} 5 a\end{array}$ & $\begin{array}{l}\text { Particle cracking } \\
\text { Interfacial decohesion } \\
\text { Particle cracking (large particle) and Matrix voiding } \\
\text { Matrix voiding }\end{array}$ & $\begin{array}{l}0.72 \pm 0.06 \\
0 \\
0.64 \pm 0.07 \\
0.10 \pm 0.05\end{array}$ & $\begin{array}{l}10 \pm 4.1 \\
\text { Not measured } \\
2.6 \pm 1.2 \\
1.6 \pm 0.8\end{array}$ \\
\hline $\begin{array}{l}\mathrm{Al}-\mathrm{Al}_{2} \mathrm{O}_{3} \\
\text { Polygonal }\end{array}$ & $\begin{array}{l}\mathrm{A} 25 p \\
\mathrm{~A} 15 p \\
\mathrm{~A} 5 p\end{array}$ & $\begin{array}{l}\text { Matrix voiding and few particle cracking } \\
\text { Matrix voiding } \\
\text { Matrix voiding }\end{array}$ & $\begin{array}{l}0.05 \pm 0.01 \\
0 \\
0\end{array}$ & $\begin{array}{l}8.4 \pm 2.4 \\
4.3 \pm 1.8 \\
1.4 \pm 0.8\end{array}$ \\
\hline $\mathrm{Al}-\mathrm{B}_{4} \mathrm{C}$ & $\begin{array}{l}\text { B60 } \\
\text { B35 } \\
\text { B20 } \\
\text { B10 } \\
\text { B5 }\end{array}$ & $\begin{array}{l}\text { Particle cracking and matrix voiding } \\
\text { Matrix voiding and few particle cracking } \\
\text { Matrix voiding and few particle cracking } \\
\text { Matrix voiding } \\
\text { Matrix voiding and reaction phase cracking }\end{array}$ & $\begin{array}{l}0.51 \pm 0.05 \\
0.12 \pm 0.03 \\
0.15 \pm 0.03 \\
0.10 \pm 0.02 \\
0.04 \pm 0.01\end{array}$ & $\begin{array}{l}12.1 \pm 4.5 \\
5.9 \pm 2.5 \\
\text { Not measured } \\
2.2 \pm 0.9 \\
1.6 \pm 0.9\end{array}$ \\
\hline
\end{tabular}

(iii) at a given size of reinforcement, the depth of the dimples nucleated by broken particles is larger than that of dimples nucleated between particles.

\section{Discussion}

\subsection{The local fracture energy}

The local fracture energy $2 \gamma_{\mathrm{pz}}$ as defined in Eq. (2) can be estimated using the model of Stüwe [25,26]. In the case of a crack propagating through the matrix (schematically illustrated in Fig. 11(a)), one obtains a fracture surface made of ductile dimples, whose formation energy per unit area is $\gamma_{\mathrm{pl}}=\frac{h_{0} k}{n+1} \int_{0}^{1} z(x)\left[\ln \left(\frac{1}{z(x)}\right)\right]^{n+1} \mathrm{~d} x$,

where $k$ and $n$ are the parameters of the in situ matrix stress-strain curve, and $h_{0}$ is the average dimple height measured on reconstructed surfaces. The function $z(x)$ describes the geometry of the fracture surface. Since any reasonable curve describing the fracture surface profile leads to almost the same result for $\gamma_{\mathrm{pl}}$ [26] the function $z(x)=x$ is used for simplicity.

Since intense plastic deformation occurs locally during microcavitation, the constitutive behaviour of the ductile aluminium matrix must be known. However, one cannot simply use the stress-strain relationship of the unreinforced matrix flow stress because of size effects: in

(a)
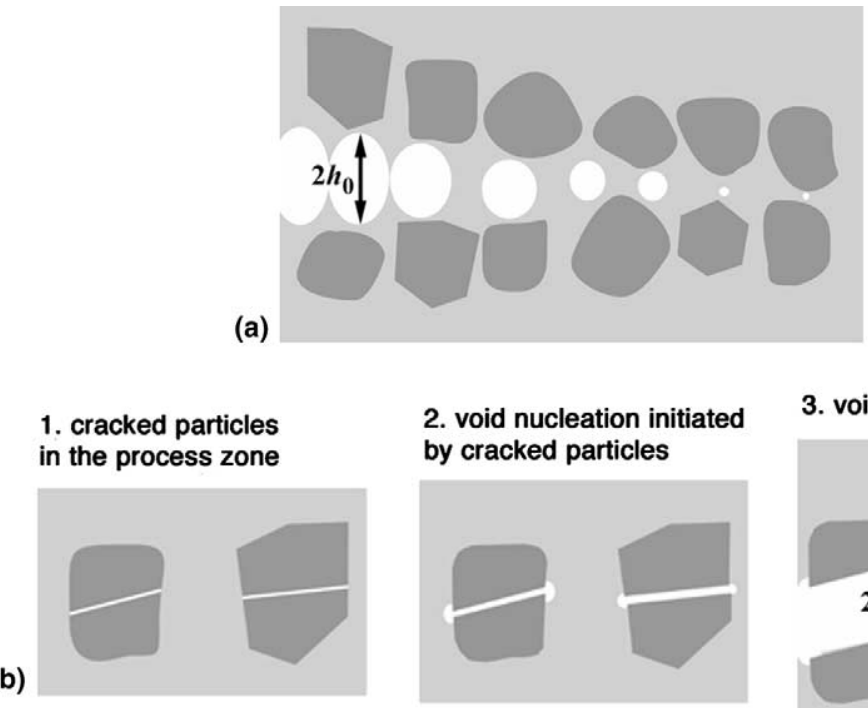

3. void coalescence

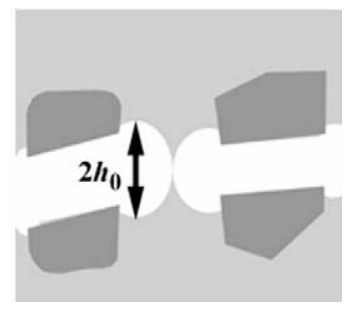

Fig. 11. Schematic description of crack initiation and propagation in the composites. (a) Voids nucleated in the matrix; (b) voids nucleated by particle cracking, crack propagation occurs by growth and coalescence of these voids. 
the present composites the in situ matrix flow stress depends on the interparticle size due to the presence of geometrically necessary dislocations, the amount of which increasing by decreasing the interparticle size [57]. In situ matrix flow curves derived for these composites in [57] were subsequently fitted by a Hollomon power hardening law

$\sigma_{\mathrm{m}, \mathrm{Al}}=k \cdot \varepsilon_{\mathrm{m}, \mathrm{Al}}^{n}$,

where $\sigma_{\mathrm{m}, \mathrm{Al}}$ and $\varepsilon_{\mathrm{m}, \mathrm{Al}}$ are the matrix flow stress and the matrix strain, respectively, $n$ is the work-hardening rate exponent, and $k$ is the strength coefficient. The fitting parameters $(n$ and $k$ ) are listed for all composites in Appendix B.

When particle fracture occurs and nucleates voids, the crack faces separate finally by coalescence of these voids, Fig. 11(b); the fracture energy of these broken particle-nucleated dimples can still be described as in Fig. 11(a), provided $h_{0}$ is known. The major difference with matrix-nucleated dimples then lies in the fact that only a fraction of the fracture surface is occupied by dimples, the remainder being covered by cracked particles. The fracture energy of particle cracking, $2 \gamma_{b}$, is simply given by the known toughness of the ceramic from which the particles are made, $G_{\text {Ic-b }}$ :

$2 \gamma_{b}=G_{\text {Ic-b }}=\left(K_{\text {Ic-b }}\right)^{2} \cdot \frac{E_{\mathrm{b}}}{1-v^{2}}$,

where $K_{\text {Ic-b }}$ is the critical stress intensity factor of the ceramic, $E_{\mathrm{b}}$ its Young's modulus, and $v$ its Poisson's ratio. Values from the literature were used (Appendix B). Adding the two contributions (ductile dimple creation and cracking of brittle ceramic particles), the mean local fracture energy $2 \gamma_{\mathrm{pz}}$ consumed to create the fracture profile in each composite reads

$2 \gamma_{\mathrm{pz}}=2 \cdot\left[f_{\mathrm{b}} \cdot \gamma_{b}+\left(1-f_{\mathrm{b}}\right) \cdot\left(\gamma_{\mathrm{pl}}\right)\right]$,

where $f_{\mathrm{b}}$ is the fraction of the fracture path occupied by broken particles, and $\gamma_{\mathrm{pl}}$ is obtained by solving Eq. (5) numerically. Based on Eq. (8), the correlations between fracture toughness and details of the fracture surface can now be discussed.

\subsection{Correlation between the local and the total fracture energy}

A plot of $J_{\mathrm{GT}}$ vs. $2 \gamma_{\mathrm{pz}}$ for all composites but the A20a (failing by interfacial decohesion, and for which $2 \gamma_{\mathrm{pz}}$ is not known) is given in Fig. 12. The global fracture energy is found to scale linearly with $2 \gamma_{\mathrm{pz}}$, being about one order of magnitude larger (this is not surprising since large plastic zones are formed around the crack tip in these materials [19]). Hence, although only a small portion of the fracture energy is spent in the process zone, it still governs the overall composite toughness for all composite systems. The global fracture energy is, in

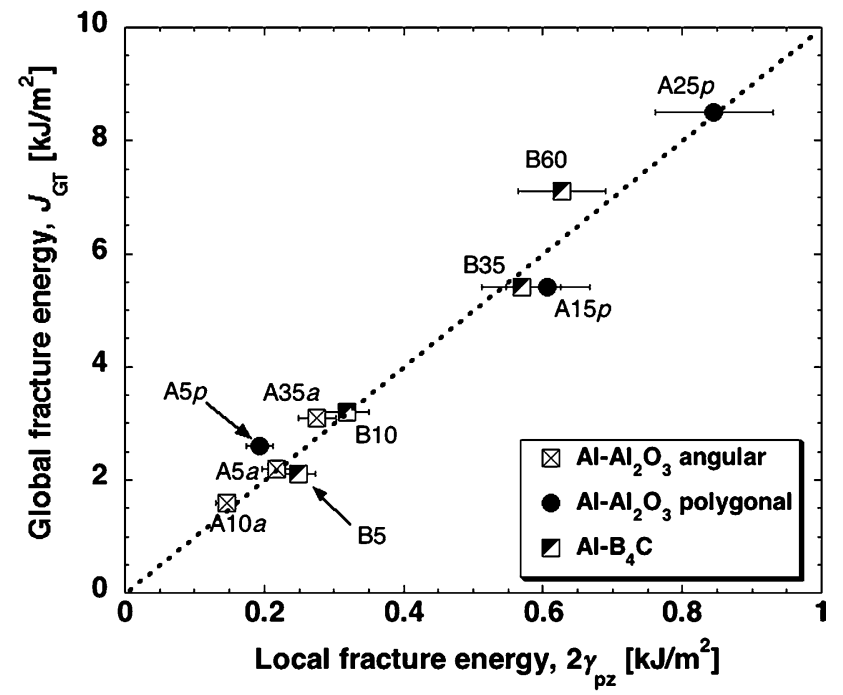

Fig. 12. Correlation between the local work of fracture as determined from Eq. (8) and from quantitative metallography, and the global fracture energy as measured at the initiation of ductile tearing.

other words, a direct amplification (by about 10) of the local work of fracture.

Interestingly, this amplification factor of 10 is also found in earlier work of this kind by Davidson on $\mathrm{Al}$ alloy $/ 15 \% \mathrm{SiC} p$ composite [18]. A factor of the same magnitude was also recently reported by Wegner and Gibson [67] for a similar ductile/brittle two-phase composite consisting of hard stainless steel infiltrated with ductile bronze.

This factor of 10 is probably too high, however. In all likelihood $\gamma_{\mathrm{pl}}$ is underestimated in the calculation that precedes because triaxiality is ignored in Stüwe's analysis. It has been reported that ductile tearing of a metal that is narrowly constrained by a surrounding rigid phase takes place under triaxiality so high that the peak stress required for voiding is typically on the order of six to eight times the metal tensile flow stress [24,68-72]. At the high ceramic fractions of these composites, the metal is highly constrained; hence the ligaments must have stretched under high triaxiality. We believe that this high triaxiality is in fact the fundamental underlying mechanism responsible for the exceptionally high toughness of these composites, because it increases the local peakstress at the crack tip during voiding, thereby generating conditions for plasticity to toughen such elastic-plastic composites according to the analysis by Tvergaard and Hutchinson [39]. This mechanism is exposed and discussed in more details in [73].

Models for voiding under high triaxiality show that although the peak stress is raised significantly, the local work of fracture $\gamma_{\mathrm{pl}}$, is only increased by a factor of two or at most three. Therefore, the values computed for $2 \gamma_{\mathrm{pl}}$ may actually be too low by a factor of around two, meaning that the amplification factor should perhaps be 
around 5 , not 10 . Also, there are sources of uncertainty other than the unknown influence of triaxiality; for example, with fine particles quantification of broken particles on the fracture surface is not as precise, while $2 \gamma_{\mathrm{pz}}$ is quite sensitive to this value. The conclusion from Fig. 12 remains, however, unchanged even after taking into account sources of error or (systematic) underestimation in $2 \gamma_{\mathrm{pl}}$ : the measured fracture toughness of the composites scales neatly and directly with the local fracture energy. On this basis, the fracture and toughening of these composites can be discussed.

\subsection{Microstructural dependence of fracture and toughen- ing in these composites}

All else being equal, the fracture toughness of materials scales linearly with the relevant microstructural length scale (dimple size, particle spacing, etc). In pure $\mathrm{Al} /$ polygonal $\mathrm{Al}_{2} \mathrm{O}_{3}$ particle composites, there is essentially no particle fracture. Therefore, the final dimple size scales linearly with the reinforcement size. Since the decrease in matrix flow stress caused by an increase in particle size is less than proportional to the particle diameter [57], the local work of fracture $2 \gamma_{\mathrm{pz}}$ increases with increasing particle size, and does so nearly in linear fashion. This in turn results in a fracture energy that increases nearly linearly with the particle diameter for these composites, Fig. 7. We note that in attempting to correlate these two parameters for a $20 \mathrm{vol} \% \mathrm{SiC}$ particle reinforced composite such a link was not found in [74]; however the author anticipated that it would be more likely that fracture surface roughness correlates with fracture toughness for PRMMCs exhibiting very ductile fracture. This is exactly what is seen in the present composites, despite the high ceramic loading and although the underlying mechanism is different. ${ }^{2}$

The toughness of pure $\mathrm{Al} /$ angular $\mathrm{Al}_{2} \mathrm{O}_{3}$ composites is lower than with polygonal particles. This is explained by particle cracking, which reduces $2 \gamma_{\mathrm{pz}}$ (Eq. (8)). Because larger particles tend to be weaker, the benefit of a larger fracture microstructural scale with larger particles is now offset by an increased propensity for particle cracking. This explains why an optimum particle size can sometimes be found.

In $\mathrm{Al}-\mathrm{B}_{4} \mathrm{C}$ composites, the particle size effect on the toughness is similarly explained: the composite with the largest particles $(60 \mu \mathrm{m})$ features the largest average dimple size, which compensates the lower matrix flow stress and the higher extent of particle cracking.

\footnotetext{
${ }^{2}$ In this reference, it was postulated that the correlation between toughness and fracture surface roughness would exist because most of the fracture energy should be spent to create the fracture surface; we show here that even for very ductile micromechanisms of fracture, most of the fracture energy is still spent in the plastic zone.
}

As the particle size, and hence the interparticle distance, decrease smaller cavities are formed, thus reducing the local fracture energy and in turn the global toughness.

At a given particle size, polygonal alumina particle composites are the toughest because the particles are strong enough not to break during crack propagation. Boron carbide reinforced composites are not as tough because some particle cracking occurs during the fracture process, while angular alumina composites are the least fracture resistant due to extensive particle cracking. A detailed analysis of the importance of particle characteristics in toughening of the present composites is presented in [73].

According to data from the literature, non-embrittled $\mathrm{Al}-\mathrm{Al}_{2} \mathrm{O}_{3}$ interfaces feature ductile fracture by microvoid coalescence [75-77]. The measured toughness of such interfaces is comprised between 0.2 and $0.6 \mathrm{~kJ} / \mathrm{m}^{2}$ $[77,78]$. This is in the range of the local fracture energy $2 \gamma_{\mathrm{pz}}$ values estimated here for the composites. In the presence of contaminants and segregants, brittle decohesion often occurs at ceramic/metal interfaces, thereby lowering the interface toughness to values on the order of $1-20 \times 10^{-3} \mathrm{~kJ} / \mathrm{m}^{2}$ [78-80] corresponding to the order of magnitude of interfacial energies [81]. We recall that in the angular $20 \mu \mathrm{m}$ alumina particle reinforced composite, interfacial decohesion is the dominant damage mechanism (Figs. 8(c) and 9(b)). This material exhibits the smallest fracture resistance of all composites: the reason must be contamination of the interface, leading to weaker interfacial bonding (given the poor properties of this composite and its anomalous behaviour, we have not sought to find the responsible chemical contaminant). Extrapolating the global vs. local curve for this composite would indicate that the local fracture energy is about $0.1 \mathrm{~kJ} / \mathrm{m}^{2}$ : this is still at least one order of magnitude above typical values of interfacial energies. Dimple formation between two decohered interfaces must therefore contribute the majority of the local work of fracture for this system. Such interfacial embrittlement effects were explained by Rice and Wang [82] and are receiving increasing attention for grainboundary fracture [34] or for fracture along metal/ ceramic interfaces [83-85].

\section{Conclusions}

- Metal matrix composites with a high volume fraction (around 50\%) of ceramic particles are produced by infiltration. Depending on the initial quality of the reinforcement and the particle size, the composites exhibit a large spectrum of fracture response, ranging from fully stable crack propagation with marked $R$-curve behaviour to unstable fracture and little $R$ curve behaviour. 
- The micromechanisms of crack propagation depend on the ceramic type, shape, and size. With a higher quality of reinforcement, the crack propagates by ductile cavitation in the matrix. For a lower quality of reinforcement, voids are nucleated by particle cracking. For a given micromechanism of fracture, the dimple size scales with the interparticle distance.

- The local work of fracture is estimated using detailed fractographic examinations and simple micromechanical models. The composite fracture energy is proportional to the estimated local fracture energy by a factor between 5 and 10 . This proportionality proves that, although the main contribution to the fracture energy is from crack-tip plastic dissipation, toughness is governed by the local work of fracture. This study thus provides experimental evidence of the "valve" effect by which macroscopic plastic deformation around the crack tip essentially serves to amplify the local work of fracture. Although the latter is small, it dictates the total material fracture toughness.

\section{Acknowledgements}

This work was funded by the Swiss National Science Foundation under Contract No. 2000-063575-00, with added support from core funding of the Swiss Federal Institute of Technology, Lausanne.
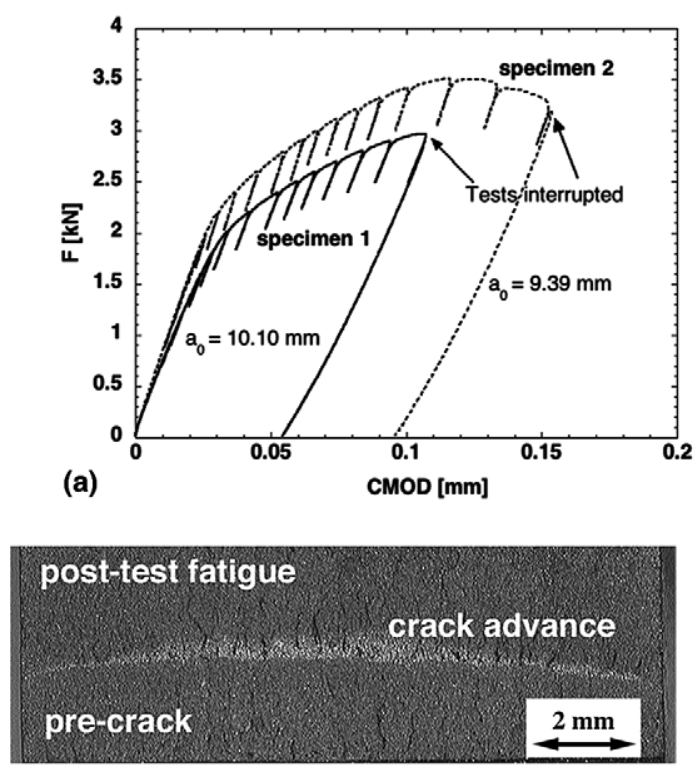

(c)

\section{Appendix A. Domain of $\boldsymbol{J}$-validity}

To support the choice of $J_{\mathrm{GT}}$ as a critical fracture parameter, two fracture tests on the A25 $p$ composite were interrupted prior to failure, and the crack front was physically marked by subsequent fatigue loading. The first test was interrupted slightly before the peak load, while the second was interrupted just beyond the peak load, Fig. 13(a). The corresponding $J-R$ curves are given in Fig. 13(b). These indicate that the first specimen was still in the initial, higher slope, portion of the $J-R$ curve, whereas the second specimen was unloaded at the beginning of the second portion (II) of the curve. The fracture surfaces of the two specimens show clearly the difference between fatigue (dark grey) and monotonous crack propagation (light grey) when examined under a binocular microscope, Fig. 13(c) and (d). It is clear from these observations that the crack indeed truly starts propagating on a macroscopic scale at the onset of Regime II on the $J-\Delta a$ curves. Prior to this transition, there is still some limited crack advance (Fig. 13(c)); hence the steeper Region I cannot be strictly ascribed to blunting as for metals and alloys; it must denote the stage of crack tip process zone formation preceding macroscopic crack growth.

\section{Appendix B. Numerical values}

See Tables 4 and 5 .
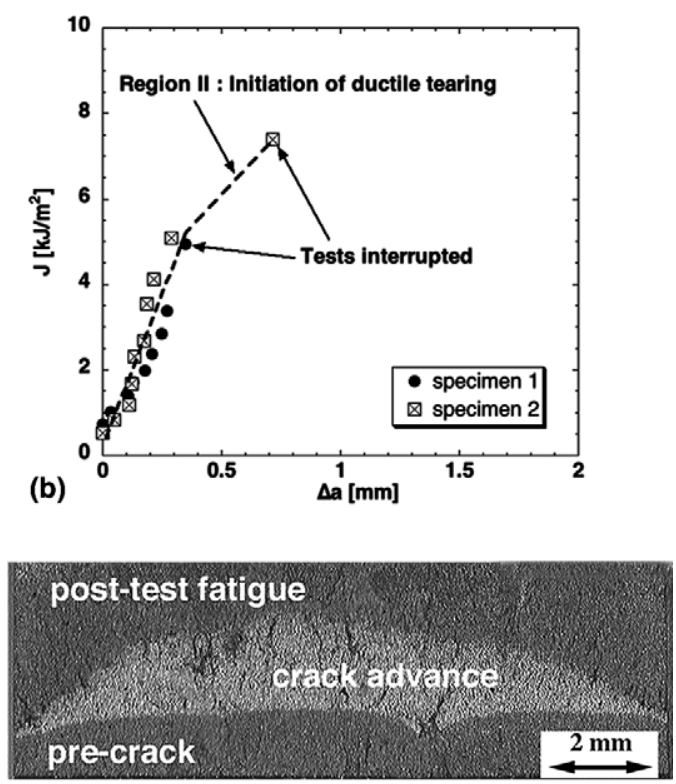

(d)

Fig. 13. Tests on A25 composite specimens arrested prior to final failure, and crack profiles subsequently marked in fatigue. (a) Load-CMOD curves, one specimen arrested just before and the other just after the peak load; (b) corresponding $J-R$ curves; (c) binocular micrograph of the fracture surface, specimen 1; (d) binocular micrograph of the fracture surface, specimen 2. 
Table 4

Fitting parameters of the Hollomon law describing the in situ matrix flow stress of the composites

\begin{tabular}{llllllllllll}
\hline Composite & $\mathrm{A} 35 a$ & $\mathrm{~A} 10 a$ & $\mathrm{~A} 5 a$ & $\mathrm{~A} 25 p$ & $\mathrm{~A} 15 p$ & $\mathrm{~A} 5 p$ & $\mathrm{~B} 60$ & $\mathrm{~B} 35$ & $\mathrm{~B} 20$ & $\mathrm{~B} 10$ & $\mathrm{~B} 5$ \\
\hline$n$ (dimensionless) & 0.21 & 0.22 & 0.23 & 0.21 & 0.27 & 0.22 & 0.20 & 0.20 & 0.21 & 0.22 & 0.23 \\
$k(\mathrm{MPa})$ & 223 & 328 & 417 & 267 & 377 & 352 & 212 & 275 & 336 & 407 & 441 \\
\hline
\end{tabular}

Table 5

Mechanical characteristics of the reinforcement

\begin{tabular}{lllll}
\hline $\begin{array}{l}\text { Reinforcement } \\
\text { materials }\end{array}$ & $\begin{array}{l}\text { Young's } \\
\text { modulus, } \\
E(\mathrm{GPa})\end{array}$ & $\begin{array}{l}\text { Poisson's ratio } \\
\text { (dimensionless) }\end{array}$ & $\begin{array}{l}\text { Toughness, } \\
K_{\mathrm{Ic}} \\
(\mathrm{MPa} \sqrt{m})\end{array}$ & \\
\hline $\mathrm{Al}_{2} \mathrm{O}_{3}$ & $345-400$ & $0.22-0.26$ & $1.5-6^{\mathrm{a}}$ & {$[86-88]$} \\
$\mathrm{B}_{4} \mathrm{C}$ & $430-480$ & $0.14-0.18$ & 3.7 & {$[88-90]$} \\
\hline
\end{tabular}

${ }^{\mathrm{a}}$ The toughness of alumina is highly dependent on purity and porosity. We used here the value of $4 \mathrm{MPa} \sqrt{\mathrm{m}}$ typically reported for high purity $\alpha$-alumina [86].

\section{References}

[1] Hunt WH, Osman TM, Lewandowski JJ. JOM 1993;45:30-5.

[2] Mortensen A. In: Masounave J, Hamel FG, editors. Proc of the Conf on Fabrication of Particulates Reinforced Metal Composites, Montréal, Qué Canada. ASM International; 1990. p. 217-33.

[3] Lloyd DJ. Int Mater Rev 1994;39:1-23.

[4] Lewandowski JJ, Singh PM. In: Lewandowski JJ, Hunt JWH, editors. Proc of the Conf on Intrinsic and Extrinsic Fracture Mechanisms in Inorganic Composite Systems. The Minerals, Metals \& Materials Society; 1995. p. 129-46.

[5] Lewandowski JJ. In: Clyne TW, editor. Comprehensive composite materials. Metal matrix composites, vol. 3. Amsterdam: Elsevier; 2000. p. $151-87$.

[6] Sinclair I, Gregson PJ. Mater Sci Technol 1997;13:709-25.

[7] Davidson DL. Composites 1993;24:248-55.

[8] Hunt WH. In: Lewandowski JJ, Hunt JWH, editors. Proc of the Conf on Intrinsic and Extrinsic Fracture Mechanisms in Inorganic Composite Systems, Las Vegas, Nevada. The Minerals, Metals \& Materials Society; 1995. p. 31-8.

[9] Leggoe JW, Hu XZ, Bush MB. Eng Fract Mech 1996;53:873-95.

[10] Kamat SV, Hirth JP, Mehrabian R. Acta Metall 1989;9:2395-402.

[11] Flom Y, Arsenault RJ. Acta Metall 1989;37:2413-23.

[12] Manoharan M, Lewandowski JJ. Acta Metall Mater 1990;38:48996.

[13] Hadianfard MJ, Heness G, Healy JC, Mai Y-W. Fatigue Fract Eng Mater Struct 1994;17:253-63.

[14] Pestes RH, Kamat SV, Hirth JP. Mater Sci Eng A 1994;189:9-14.

[15] Rabiei A, Kim BN, Enoki M, Kishi T. Mater Trans, JIM 1996;37:1148-55.

[16] Song SG, Shi N, Gray GT, Roberts JA. Metall Mater Trans 1996;27A:3739-46.

[17] Pandey AB, Majumdar BS, Miracle DB. Metall Mater Trans A 2000;31:921-36.

[18] Davidson DL. Metall Trans A 1987;18:2115-28.

[19] Miserez A, Rossoll A, Mortensen A, Eng Fract Mech 2003, accepted.

[20] Knott JF, Boccaccini AR. In: Meyers MA, Armstrong RW, Kirchner HOK, editors. Mechanics and Materials: Fundamentals and Linkages. New York: John Wiley \& Sons; 1999. p. 399-427.

[21] Kolednik O. Eng Fract Mech 1991;38:403-12.

[22] Turner CE, Kolednik O. Fatigue Fract Eng Mater Struct 1994;17:1089-107.

[23] Stampfl J, Kolednik O. Int J Fract 2000;101:321-45.

[24] Poech MH, Fischmeister HF. Eng Fract Mech 1992;43:581-8.
[25] Stüwe HP. Eng Fract Mech 1980;13:231-6.

[26] Stüwe HP. In: Nemat-Nasser S, editor. Proc of the Conf on Threedimensional Constitutive Relations and Ductile Fracture. Dourdan: N-H Publishing; 1981. p. 213-21.

[27] Gilman JJ. In: Lee EH, Symonds PS, editors. Plasticity. Oxford: Pergamon Press; 1960. p. 43-99.

[28] Rice JR. In: Yokobori T, Kawsaki T, Swedlow JL, editors. Proc of the Third Int Conf on Fracture, Sendai. Japanese Soc. for Strength and Fracture of Metals; 1965. p. 309-40.

[29] Jokl ML, Vitek V, McMahon CJ. Acta Metall 1980;28:1479-88.

[30] Suo Z, Shih CF, Varias AG. Acta Metall Mater 1993;41:1551-7.

[31] Lipkin DM, Beltz GE. Acta Mater 1996;4:1287-91.

[32] Lipkin DM, Clarke DR, Beltz GE. Acta Mater 1996;44:4051-8.

[33] Beltz GE, Rice JR, Shih CF, Xia L. Acta Mater 1996;44:3943-54.

[34] Beltz GE, Lipkin DM. MRS Bull 2000;25:21-6.

[35] Kysar JW. J Mech Phys Solids 2003;51:795-824.

[36] Gerberich WW. In: Wells JM, Landes JD, editors. Fracture: interactions of microstructure, mechanisms and mechanics. Warrendale, PA: TMS; 1984. p. 49-74.

[37] Hirth JP, Froes FH. Metall Trans 1977;8A:1165-76.

[38] Pineau A. In: Argon AS, editor. Topics in fracture and fatigue. New York: Springer; 1992. p. 197-234.

[39] Tvergaard V, Hutchinson JW. J Mech Phys Solids 1992;40:1377-97.

[40] Tvergaard V, Hutchinson JW. Int J Solids Struct 1996;33:3297308.

[41] Siegmund T, Brocks W. In: Paris PC, Jerina KL, editors. Fatigue and fracture mechanics: vol 30. ASTM STP 1360. West Conshohocken, PA, USA: ASTM; 2000. p. 139-51.

[42] Li H, Chandra N. Int J Plasticity 2003;19:849-82.

[43] Tvergaard V. In: Willis JR, editor. Proc of the Conf on IUTAM Symposium on Nonlinear Analysis of Fracture. Dordrecht: Kluwer Academic Publishers; 1997. p. 93-104.

[44] Hutchinson JW. In: Willis JR, editor. Proc of the Conf on IUTAM Symposium on Nonlinear Analysis of Fracture. Dordrecht: Kluwer Academic Publishers; 1997. p. 81-91.

[45] Hutchinson JW, Evans AG. Acta Mater 2000;48:125-35.

[46] Michaud VJ. In: Suresh S, Mortensen A, Needleman A, editors. Fundamentals of metal matrix composites. London: ButterworthHeinemann; 1993. p. 3-22.

[47] Mortensen A, Michaud VJ, Flemings MC. JOM 1993;45:36-43.

[48] Mortensen A. In: Clyne TW, editor. Comprehensive composite materials. Metal matrix composites, vol. 3. Amsterdam: Elsevier; 2000. p. $521-54$

[49] Garcia-Cordovilla C, Louis E, Narciso J. Acta Mater 1999;47:4461-79.

[50] SanMarchi C, Kouzeli M, Miserez A, Moser B, Rossoll A, Weber L, et al.. In: Song J, Yin R, editors. ICETS 2000-Session 3: Proc of the Advanced Materials Conference, Beijing, China. New World Press; 2000. p. 74-82.

[51] Kouzeli M, Weber L, SanMarchi C, Mortensen A. Acta Mater 2001;49:3699-709.

[52] Miserez A, Fracture and toughening of high volume fraction ceramic particle reinforced metals. Ph.D. Thesis, No. 2703, Ecole Polytechnique Fédérale de Lausanne - EPFL. Available from: library.epfl.ch/theses/?display $=$ detail\&NR $=2703$.

[53] Viala JC, Bouix J, Gonzalez G, Esnouf C. J Mater Sci 1997: 4559-73.

[54] Meyer FD, Hillbrecht H. J Alloys Compd 1997;252:98-102. 
[55] Viala JC, Peronnet M, Bosselet F, Bouix J, In: Massard T, Vautrin A, editors. Proc of the 12th Int Conf on Composite Materials, Paris, 1999 ed.

[56] Kouzeli M, SanMarchi C, Mortensen A. Mater Sci Eng 2002;A337:264-73.

[57] Kouzeli M, Mortensen A. Acta Mater 2002;50:39-51.

[58] E 1737-96: Standard test method for $J$-integral characterization of fracture toughness. Philadelphia: ASTM; 1996. p. 957-80.

[59] Brocks W, Schmitt W. In: Kirk M, Bakker A, editors. Constraints effects in fracture, theory and applications: vol 2. ASTM STP 1244. Philadelphia: ASTM; 1995. p. 209-31.

[60] Merkle JG. In: Reuter WG, Underwood JH, Newman JC, editors. Fracture mechanics: vol 26. ASTM STP 1256. Philadelphia: ASTM; 1995. p. 3-40.

[61] Parks DM. In: Blauel JG, Schwalbe K-H, editors. Proc of the European Symposium on Elastic-Plastic Fracture Mechanics: Defect Assessment in Components - Fundamentals and Applications, Freiburg, Germany. London: Mechanical Engineering Publications; 1991. p. 205-31.

[62] Stampfl J, Scherer S, Gruber M, Kolednik O. Appl Phys A 1996;63:341-6.

[63] Stampfl J, Scherer S, Berchthaler M, Gruber M, Kolednik O. Int J Fract 1996;78:35-44.

[64] Anderson TL. Fracture mechanics. 2nd ed. Boca Raton (FL): CRC Press; 1995.

[65] Hutchinson JW, Paris PC. In: Landes JD, Begley JA, Clarke GA, editors. Elastic-plastic fracture. ASTM STP 668. ASTM; 1979. p. $37-64$.

[66] Hutchinson JW. J Appl Mech 1983;50:1042-51.

[67] Wegner LD, Gibson LJ. Int J Mech Sci 2001;43:1771-91.

[68] Ashby MF, Blunt FJ, Bannister M. Acta Metall 1989;37:1847-57.

[69] Sigl LS, Mataga PA, Dalgleish BJ, McMeeking RM, Evans AG. Acta Metall 1988;36:945-53.

[70] Tvergaard V. Comput Mech 1997;20:186-91.
[71] Tvergaard V. Int J Mech Sci 2000;42:381-95.

[72] Bannister M, Ashby MF. Acta Metall Mater 1991;39:2575-82.

[73] Miserez A, Müller R, Rossoll A, Weber L, Mortensen A, In: Proc of the 13th Int Conf on the Strength and Fracture of Materials Special issue (ICSMA 13), Budapest, 2003, Mater. Sci. Eng. A, accepted for publication.

[74] Davidson DL. J Mater Sci 1989;24:681-7.

[75] Evans AG, Dalgleish BJ. Acta Metall Mater 1992;40:s295-306.

[76] Evans AG, Dalgleish BJ. Mater Sci Eng A 1993;162:1-13.

[77] McNaney JM, Cannon RM, Ritchie RO. Acta Mater 1996;44:4713-28.

[78] Evans AG, Hutchinson JW, Wei Y. Acta Mater 1999;47:4093113.

[79] Lipkin DM, Clarke DR, Evans AG. Acta Mater 1998;46:4835-50.

[80] Wei Y, Hutchinson JW. Int J Fract 1999;95:1-17.

[81] Saiz E, Cannon RM, Tomsia AP. Acta Mater 1999;47:4209-20.

[82] Rice JR, Wang JS. Mater Sci Eng A 1989;107:23-40.

[83] Zhang W, Smith JR, Evans AG. Acta Mater 2002;50:3803-16.

[84] Korn D, Elssner G, Cannon RM, Rühle M. Acta Mater 2002;50:3881-901.

[85] Cannon RM, Korn D, Elssner G, Rühle M. Acta Mater 2002;50:3903-25.

[86] Sglavo VM, Trentini E, Boniecki M. J Mater Sci Lett 1999;18:1127-30

[87] Cawley JD. In: Buschow KH, Flemings MC, Kramer EJ, Cahn RW, Ilschner B, Mahajan S, editors. Encyclopedia of materials science and technology. Amsterdam: Elsevier; 2001. p. 524-33.

[88] Tressler RE. In: Buschow KH, Flemings MC, Kramer EJ, Cahn RW, Ilschner B, Mahajan S, editors. Encyclopedia of materials science and technology. Amsterdam: Elsevier; 2001. p. 8913-21.

[89] DeWith G. J Mater Sci 1984;19:457-66.

[90] Parvizi-Majidi A. In: Comprehensive composite materials. Fiber reinforcements and general theory of composites, vol. 1. Amsterdam: Elsevier; 2000. p. 175-98. 